\title{
The intercalated BSc in sports and exercise medicine at Barts and The London School of Medicine and Dentistry
}

\author{
Dylan Morrissey ${ }^{1}$ \\ James L. Nutt ${ }^{2}$ \\ Roshana Mehdian² \\ Nicola Maffulli, ${ }^{1,3}$
}
1 Centre for Sports and Exercise Medicine, Queen Mary University of London, Barts and The London School of Medicine and Dentistry, Mile End Hospi- tal, London, UK
2 Dundee University School of Medicine, Dundee, Scotland
3 Department of Physical and Rehabilitation Medicine, University of Salerno, Azienda Ospedaliera San Gio- vanni Di Dio e Ruggi d'Aragona, Salerno, Italy

Corresponding author:

Dylan Morrissey

Centre for Sports and Exercise Medicine,

Queen Mary University of London,

Barts and The London School of Medicine and Dentistry, Mile End Hospital, London, UK

Head of Department of Phisical and Rehabilitation

Medicine, University of Salerno, Azienda Ospedaliera San Giovanni Di Dio e Ruggi d'Aragona, Salerno, Italy

E-mail: d.morrissey@qmul.ac.uk

\section{Summary}

Object: To report about the intercalated Bsc(Hons) in Sports and Exercise Medicine at Barts and The London School of Medicine and Dentistry (BLSMD), Queen Mary University of London.

Design: Educational study.

Setting: The course is currently in its tenth year, providing medical students with the opportunity to develop knowledge in the field of Sports and Exercise Medicine (SEM) during one academic year of full time study.

Participants: There have been more than 150 graduates, and 22 students are enrolled for the 2012-13 academic year on what has been the most popular and largest intercalated degree at BLSMD in recent years. External applicants typically make up $30-40 \%$ of entrants.

Results: Equal weighting on taught modules and a portfolio of research activity provides a strong foundation in Sports and Exercise Medicine, and equips successful students with evidence based translational skills, and the opportunity to perform publishable research.
Conclusion: This article outlines the increasing demand for Sports and Exercise Medicine education, and how the course prepares graduates for practising SEM as a sub-specialist interest or to compete for entry into the Specialist Trainee training route.

KEY WORDS: education, curriculum, sports (and exercise) medicine.

\section{Background}

In the last decade, Sports and Exercise Medicine (SEM) in the UK has emerged as a recognised specialty with its own higher specialist training programme. This has enabled a number of new ventures within medical education to aid the training and education of future SEM practitioners. It was recognised in the early part of the decade that there was the potential for SEM to become integrated within the undergraduate medical curriculum. Following the General Medical Councils paper entitled Tomorrows doctors, students should be given the opportunity to study, in depth, areas of particular interest, and that this would include SEM ${ }^{1}$. Medical students would prefer more exposure to the specialty, and SEM education may become part of the compulsory curriculum ${ }^{2}$. These factors were partly responsible for the creation of an intercalated Bsc (iBSc) in SEM at Barts and the London Medical School. The iBSc is co-located in a dedicated training site for SEM, alongside the oldest SEM MSc programme in the UK, and a well-established team of expert academic clinicians. Now in its $30^{\text {th }}$ year, the MSc programme has trained many of the highest profile SEM physicians in the UK and overseas. Many graduates continue to be intimately involved with iBSc course delivery in support of the core team of clinical- academic staff and the associated team of clinical experts. It was recognised in 2001 that there was an unaddressed desire for undergraduate medical students to study SEM, and a corresponding potential to deliver a high quality course. The course was supported by the intercalated programme lead and board, while the additional stimuli of the Olympic bid, with which the course team and former graduates were closely involved, and an increasing local focus on management of long term conditions provided further weight to the argument in favour of the proposed degree. This paper describes how the course team designed, implemented and developed an Intercalated BSc in SEM, which we believe was the first of its kind to be intro- 
duced in the UK. The subsequent experience of course delivery is also described. Other courses focusing on sports science pre-existed the described course but did not, and do not, map closely to the SEM training curriculum nor have a base in an established clinical-academic SEM centre. The development of this course heralds the recognition of SEM as a discrete speciality.

\section{Method}

\section{Aims of the course}

Taught aspects:

- To gain an understanding of sports injury, including aetiology, pathology, assessment principles and management options;

- To understand the prevention and treatment of common medical problems that occur in sport;

- To understand the benefits and potentially adverse effects of exercise as a health tool, both for the healthy and for those with disease;

- To understand the principles of biomechanics, and relate these to specific body areas and related pathology;

- To understand the principles of rehabilitation, including sports-specificity;

- To understand common methods of research and basic statistical principles;

- To develop genre-specific writing skills that underpin scientific communication and dissemination.

\section{Research project:}

1) To enable students to develop and use the skills required to carry out a formal research project in Sports and Exercise Medicine;

2) To enable the students to develop and maintain evidence-based practice through enhanced literature critiquing skills;

3) To write a structured literature review and research project in a format suitable for publication in a recognised journal (British Journal of Sports Medicine).

Full details of course, module and research aims and learning outcomes can be found on the course website < http://www.smd.qmul.ac.uk/undergraduate/intercalated/sem/index.html $>$.

\section{Typical cohorts and eligibility criteria}

The iBSc in SEM is offered to students after their $3^{\text {th }}$ or $4^{\text {th }}$ year in undergraduate medicine at any UK or international medical school with a complementary curriculum. Non MBBS students are not admitted, although many enquiries are received. The SEM course is in its tenth year, and currently accommodates 22 students in the academic year 2012-2013. Students are selected at interview based on academic ability, reference from a tutor, their curriculum vitae, and a short essay on a set topic which is marked within the SEM department. For the academic year 2010-11, the essay title was "The London 2012 Olympics will not benefit Londoners: Discuss" - a topic designed to evaluate students' ability to formulate and express a multi-dimensional argument under timed conditions. For the current year, we focussed on critiquing articles by ex-students on injury, exercise as a health tool and SEM professional issues. The course team particularly assess students' insight into the speciality, existing research methods knowledge, and what the students bring from previous experience. Applications from external students are encouraged, following the same admission process as internal students. Typically the course receives the majority of external students applying to the portfolio of intercalated degrees at BLSMD, perhaps reflecting the unique nature of the course. External students are twinned with internal students at induction day to facilitate their transition between medical schools. Sporting participation typically provides another bridge between newly introduced student groups.

\section{Course structure}

To meet the aims, the structure of the course is modular (Table 1) over one academic year split into two semesters.

The taught component of the course begins with two taught modules. Research methods is purposefully included in semester one to prepare the students for their project work. Injury and medical problems in sport is also in semester one and gives early clinical insight and practical training that helps students interact with clinicians in later clinical visits and clinical research recruitment. Semester two comprises of the 'Exercise as a health tool' and 'Biomechanics and rehabilitation' modules.

Table 1. Taught modules, semester structure, and academic credit accrued.

\begin{tabular}{lll}
\hline Module & Semester & Academic credit (level 6) \\
\hline Injuries and Medical Problems in Sport & 1 & 15 \\
\hline Research Methods in Sports Exercise Medicine & 1 & 15 \\
\hline Biomechanics and Rehabilitation & 2 & 15 \\
\hline Exercise as a Health Tool & 2 & 15 \\
\hline Research Project & $1-2$ & 60 \\
\hline
\end{tabular}




\section{Results}

\section{Research Methods in SEM}

Through a series of lectures, seminars and interactive workshops, students learn how different types of research relate to SEM. This module involves formal lectures on different methodologies with examples drawn from the field, and supported by knowledge application tasks. Critical appraisal skills are taught, alongside a detailed introduction to statistical analysis. Small group work helps develop students' research questions and proposals in preparation for subsequent data collection. The summatively assessed module is supported by formative weekly research support tutorials promoting research skills such as the use of statistical and manuscript referencing packages, the practicalities of obtaining informed consent and project specific problem-solving. Further, there is a weekly student-led, staff-facilitated journal club.

\section{Injuries and Medical Problems in Sport}

Students are taught about the evolving role of the SEM physician using interactive lectures and practical sessions, delivered by the core team and previous MSc graduates. This module describes common injuries and practical examination skills required to diagnose them. Further, medical conditions of particular relevance to sport are covered, as are some basics of exercise physiology and the effects of differing environmental conditions on exercise. The module is complemented by a series of advanced musculoskeletal anatomy seminars using mixed media including high quality prosections.

\section{Biomechanics and Rehabilitation}

Following teaching in sports injury, students are taught the relationship of biomechanics with injury and subsequent rehabilitation. This module teaches the theoretical basis of biomechanical assessment and sports specific rehabilitation. Practical application of the principles are taught in the Sports Rehabilitation Gymnasium and in the Human Performance Laboratory, fully equipped with motion capture technology. Students are expected to apply this knowledge to design individual assessment and rehabilitation programmes.

\section{Exercise as a Health Tool}

This module aims to link the available evidence regarding exercise effects with long term condition management in the general population and their healthcare needs. These conditions include diabetes, cardiovascular disease and depression. Students are taught about specific exercise prescrip- tions supplemented by clinical visits to see how the theory they have been taught is applied in practice. A recent innovation has been the incorporation of quantitative fitness testing and activity monitoring and testing in preparation of the coursework element. This innovation has been delivered in consultation with the college occupational health department and supported by a small teaching grant, thus further embedding the course within the college community. Exercise as a health tool is the only module shared with the MSc programme in terms of content delivery, although it is assessed separately. In early years the research methods module was also co-delivered but this was altered because of consistent negative feedback form both cohorts. Essentially, the MSc students felt threatened by the contemporary study skills of the under-graduate students while the BSc students felt threatened by the clinical experience of the MSc students. Further, the MSc students design and deliver their own projects, and therefore require some content that is less applicable to the BSc students. Most of all, the growth in student numbers on both courses rendered the combined seminar and small group work approach impractical with a group of more than 30, there now being a combined total of 75 students per year enrolled between the two courses.

\section{Research Project}

Students are required to undertake an original piece of research, which involves input to project design, data collection and analysis. Along with the literature review the project contributes half the academic credit making up the BSc award. Research topics are collated by the course lead based from departmental priorities, and incorporating numerous academic, sporting and clinical external collaborators prior to arrival of a new cohort, and presented to the students at induction day to facilitate an early start and optimal delivery. The projects are diverse in design, with a choice of in vivo human performance measurement in health and disease, cellular laboratory work, field work, application of survey methods, and educational interventions. Further, efforts are made to provide a balance of individual and group projects, where each student has a clearly identified unique thread but some peer support is available with complex data collection.

Students are expected to produce a piece of high quality research with the potential for publication. Research report and literature reviews are written in scientific peer review journals style, and an oral presentation must be delivered at the end of the academic year. To assist students in writing a scientific paper and complete their written coursework, they now attend a specially designed 'Thinking Writing' course with the aid of two grants from QMUL and the Higher Education Academy. Ten hours of writing tutorials are co-delivered by two tutors in four sessions in which students are guided 


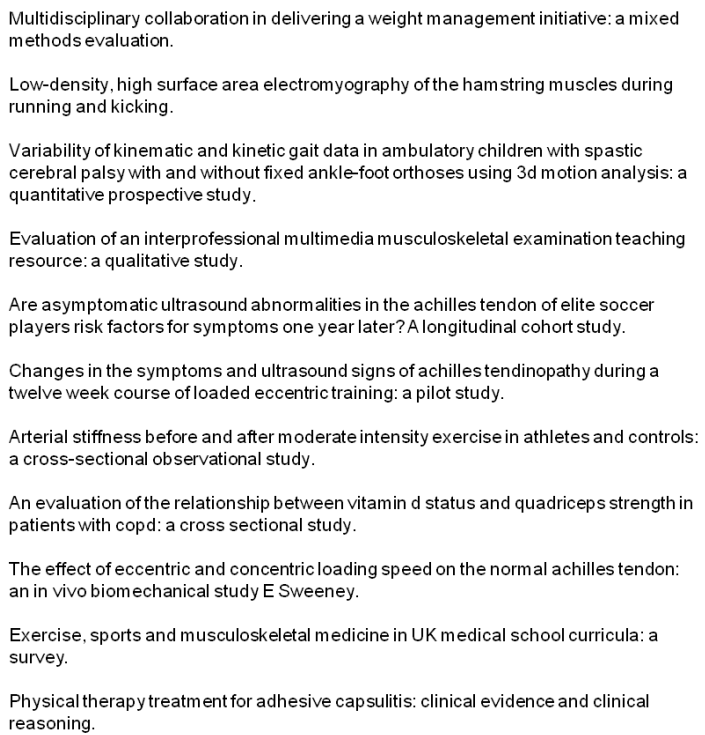

The effect of eccentric and concentric loading speed on the normal achilles tendon: an in vivo biomechanical study $E$ Sweeney.

Exercise, sports and musculoskeletal medicine in UK medical school curricula: a survey.

Physical therapy treatm ent for adhesive capsulitis: clinical evidence and clinical reasoning.

Figure 1. A sample of project titles from the year 2009-10.

through a series of exercises building from reflection on previous reading and writing tasks via genre-specific stylistic analysis towards activities designed to facilitate high level scientific writing. The writing developer helps to raise awareness of how genre-specific features could be identified textually and to offer ways of helping students to achieve the same or similar standards when writing their own projects. Examples of recent project titles are listed in Figure 1. The publication rate from student work has steadily improved. No full papers were published from the first year of the course but several conference presentations were given, and the subsequent conversion of student work to publi- cation standard has now reached $95 \%$ for peer reviewed conference presentation (2009-10 cohort), and $30 \%$ for full paper conversion at 24 months post-graduation (2008-9-10-11 cohorts). More importantly, the potential publication rate to publication is judged to be $60 \%$, which is now being facilitated via a 'writing retreat' approach.

\section{Student assessment}

The module results and the research project contribute $50 \%$ each towards the total BSc mark (Tab. 2). On completion of the degree, the University of London under-graduate degree classification range applies, with the pass mark considered to be $40 \%$, and a final mark of or over $70 \%$ classified as a First Class Honours. A range of assessment tools, both as coursework and formally examined components, are used so as not to advantage or disadvantage students with particular skill sets (Tab. 2).

\section{Resource implications}

This course is resource intensive. Approximately one third of a Senior Clinical Lecturer's time is spent organising, co-ordinating and delivering the course, supported by the input from a variety of other internal and visiting academics and clinicians. Each module has an additional academic lead within the centre, and students require two project supervisors. The centre research and teaching activities are supported by 1.5 whole time equivalent project supervisor/teaching assistants, who also fulfil other roles within the centre but have student project support as their priority. Administrative support is also necessary. Each student has a pastoral support tutor and regular access to the course lead as per published office hours. Despite the

Table 2. Module and research project assessment profiles.

\begin{tabular}{|c|c|c|c|}
\hline Module & Assessment balance & \multicolumn{2}{|l|}{ Examination mode } \\
\hline $\begin{array}{l}\text { Injuries and Medical Problems } \\
\text { in Sport }\end{array}$ & $\begin{array}{l}\text { Coursework } 30 \% \\
\text { Examination } 70 \%\end{array}$ & \multicolumn{2}{|c|}{$\begin{array}{l}\text { Case scenario, based on interview with a real patient } \\
\text { supervised by a course team member. } \\
\text { Multiple choice questionnaire (single best answer) and } \\
\text { short answer questions. }\end{array}$} \\
\hline Exercise as a Health Tool & $\begin{array}{l}\text { Coursework } 30 \% \\
\text { Examination } 70 \%\end{array}$ & \multicolumn{2}{|c|}{$\begin{array}{l}\text { Patient presentation (oral). } \\
\text { Multiple choice questionnaire (single best answer) and } \\
\text { short answer questions. }\end{array}$} \\
\hline Research Methods in SEM & $\begin{array}{l}\text { Coursework } 90 \% \\
\text { Examination } 0 \%\end{array}$ & \multicolumn{2}{|c|}{$\begin{array}{l}\text { Research proposal and article critique. } \\
\text { Greater than } 80 \% \text { punctuality and attendance } \\
\text { counts for } 10 \% \text {. }\end{array}$} \\
\hline Biomechanics and Rehabilitation & $\begin{array}{l}\text { Coursework } 0 \% \\
\text { Examination } 100 \%\end{array}$ & \multicolumn{2}{|c|}{$\begin{array}{l}\text { NA } \\
\text { Multiple choice questionnaire (single best answer) and } \\
\text { short answer questions. }\end{array}$} \\
\hline Research Project & \multicolumn{2}{|c|}{$\begin{array}{l}\text { Literature review on a subject ideally relevant to project, } \\
\text { with title agreed in semester one. } \\
\text { Research project report. } \\
\text { Presentation of work as formal conference presentation. } \\
\text { Viva voce performance. }\end{array}$} & $\begin{array}{l}30 \% \\
40 \% \\
20 \% \\
10 \%\end{array}$ \\
\hline
\end{tabular}




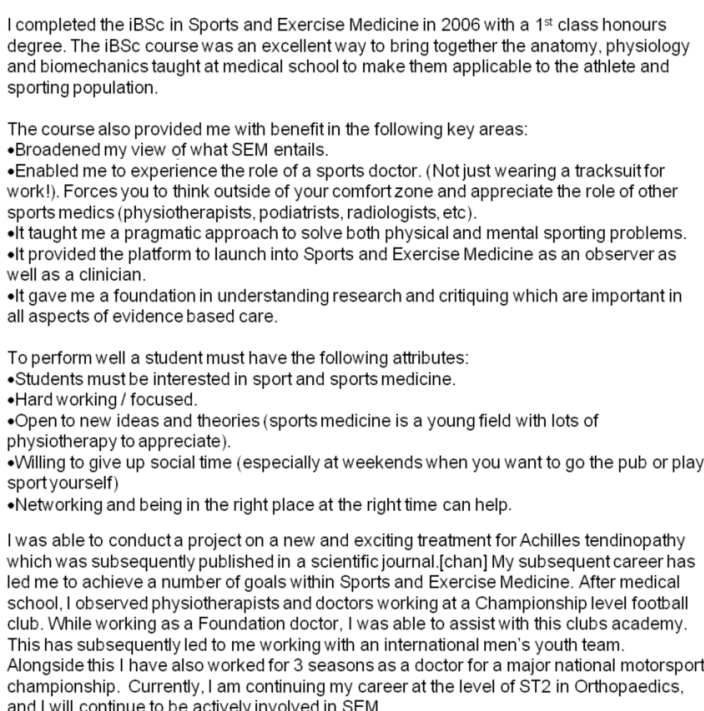

To perform well a student must have the following attributes: - Students must be interested in sport and sports medicine.

- Hard working / focused.

- Open to new ideas and theories (sports medicine is a young field with lots of

physiotherapy to appreciate).

-Willing to give up social time (especially at weekends when you want to go the pub or play sportyourself)

-Networking and being in the right place at the right time can help

I was able to conduct a project on a new and exciting treatment for Achilles tendinopathy which was subsequently published in a scientific journal. [chan] My subsequent career has which was subsequently published in a scientfic journal. [chan] My subsequent career has led me to achieve a number of goals within Sports and Exercise Medicine. After medical school, lobserved phys the rapists and doctors working at a Championship level football club. While working as a Foundation doctor, I was able to assist with this clubs academy. This has subse chich

and will continue to be actively involved in SEM.

Figure 2. Case study of student experience and subsequent career impact.

resources employed in course delivery, the course is in surplus based on current fee arrangements.

\section{Case study}

One of the first students to complete the course has now forged a career in the field of Sports and Exercise Medicine. His secrets to success on the course and his career pathway are outlined in Figure 2.

\section{Discussion}

Increasing pressure for medical undergraduate curricula to incorporate a broader range of specialties, including SEM, has resulted from the publication of Tomorrows' doctors $(2003 / 2009)^{3}$. The provision of an iBSc in Sports and Exercise Medicine allows students interested to learn about the subject in greater depth while developing research skills. It is still unclear who should be teaching Sports and Exercise Medicine at an undergraduate level ${ }^{4}$. The use of a dedicated iBSc is an answer, and the format designed and implemented in our setting is an effective solution for a sub-sample of medical students. Previous studies have described the implementation of integrated BSc courses in a wide range of topics including Primary Health Care ${ }^{1}$. This paper is the first to describe a method of implementing a SEM iBSc. The high number of applicants from within QMUL is evidence of the popularity of the subject and reputation of the course. Further, most applicants intend to include SEM as a sub-speciality within orthopaedics, rheumatology, emergency medicine, public health or general practice. The demand for the course reflects a consistent desire to augment existing musculoskeletal knowledge and skills alongside a better understanding of the health benefits of exercise. The high number of external applicants may also be due to the reputation of the course, with external applicants having often been recommended to apply by previous graduates, but informal survey suggests that the main reason is the unique nature of the course. The location of the course within a specialist training centre that has well established clinical and academic activity brings many benefits. The SEM centre is staffed by a diverse mix of professions, including specialist physiotherapists and SEM physicians, and is led by an Orthopaedic Surgeon with a special interest in SEM ${ }^{5}$. We believe that the involvement of a spectrum of relevant clinicians provides the students with a broad insight into the specialty, reflecting the inter-professional nature in which SEM care is delivered6. Interaction with these clinicians reinforces clinical application of learned theory and skills, enables students to refine their research question and, in some instances, recruit subjects for study ${ }^{7}$.

A recent survey by two iBSc students revealed the lack of consensus concerning the place of SEM in relation to more established specialities such as orthopaedics, rheumatology and public health ${ }^{8}$. Further, the survey demonstrated the lack of engagement with the exercise medicine components of the speciality among the current crop of SEM specialist trainees. A student recently surveyed all UK medical schools, demonstrating the increasing importance given to exercise medicine for prevention and treatment of long term conditions ${ }^{9}$. The inclusion of the exercise as a health tool module, opportunity to prescribe multi-factorial interventions including exercise and fitness testing for real patients and future career plans including general practice as well as SEM mean the imbalance between sports and exercise medicine components is different amongst course graduates who are now publishing relevant work ${ }^{10,11}$.

The SEM course has evolved over time, and has become more than just teaching delivery. The students bring energy and drive, and are exceptionally academically able. This impetus has been harnessed to the benefit of the centre in many ways. Capacity for supervision of student research was the primary barrier to course expansion in the early years of the course, but improved infra-structure and a switch to targeting student research to seed or complement funded research activity has yielded significant outputs ${ }^{12,13}$. This is best shown by the increasing publication rate, and also by the centre's increasing level of funded research activity. Work done by the students has helped build important collaborations within the university and also professional sport ${ }^{14-16}$.

The Queen Mary University of London iBSc in Sports and Exercise Medicine has established itself during the past decade as a popular and well subscribed course for undergraduate medical students. The course aims to produce graduates who are research motivated and have the skills required should they wish to pursue an academic career. Students under- 
taking an intercalated iBSc degree are significantly more likely to perform better in subsequent medical school examinations, and that this will further contribute to higher academic ranking to enter specialty training ${ }^{17}$. There is some evidence of an untapped demand for greater teaching provision at under-graduate level, with the QMUL experience providing concrete evidence that SEM teaching by means of an intercalated BSc in sports and exercise medicine can result in positive educational and academic outcomes.

\section{Acknowledgements}

The authors would particularly like to acknowledge former staff Dr Eleanor Tillett and Dr Zoe Hudson for their efforts in course design, delivery and development. Also acknowledged are Dr Christian Barton, Professor Steve Greenwald, Mr Peter Hamlyn, Professor Bruce Kidd, Mrs Alison O'Brien, Dr Mark Perry, Dr Chris Rufford, Dr Hazel Screen, Ms Claire Small, Dr Ese Stacey, Dr Richard Twycross-Lewis and Dr Victoria Tzortziou-Brown. The support of the intercalated degree board and external examiners is also gratefully acknowledged. Finally, thank you to Dominic O'Dowd for the interview piece.

\section{Competing Interests and funding}

The authors report no declarations of competing interest. The Queen Mary University of London ESD fund and Thinking Writing initiatives are gratefully acknowledged for funding specific course developments mentioned in the text above. The Higher Education Academy (MEDEV) is also acknowledged for funding writing development.

\section{References}

1. Cullen M, Mcnally M, O'Neil SO, Macauley, D. Sport and exercise medicine in undergraduate medical schools in the United Kingdom and Ireland. Br J Sports Med 2000; 34:244-245.

2. Baby, B. What is sports medicine? Medical students don't know. Br J Sports Med 2000; 34:7.

3. Chan O, O'Dowd D, Padhiar N, et al. High volume image guided injections in chronic Achilles tendinopathy. Disabil Rehabil 2008; 19:1-12.

4. Tomorrow's Doctors, General Medical Council (UK) available at www.gmc-uk.org. Version: 1, 1993, 2, 2003, 3, 2009. Accessed Feb 2011.
5. Macleod DAD. Intercollegiate Board for Sport and Exercise Medicine Br J Sports Med 2000; 34:235.

6. Griffin C, Chung C, Tzortziou-Brown V, Morrissey D. Evaluation of an interprofessional multimedia musculoskeletal examination teaching resource: a qualitative study. $\mathrm{Br} J$ Sports Med 2011; 45:e1 doi:10.1136/bjsm.2010.081554.20.

7. Jangra A, Perry M, Maffulli N, Malliaras P, Morrissey D. Changes in the symptoms and ultrasound signs of achilles tendinopathy during a twelve week course of loaded eccentric training: a pilot study. $\mathrm{Br} J$ Sports Med 2011; 45:e1 doi:10.1136/bjsm.2010.081554.22.

8. O'Halloran P, Tzortziou-Brown V, Morgan K, Maffulli N, Perry, Morrissey D. The role of the sports and exercise medicine physician in the National Health Service: a questionnairebased survey. Br J Sports Med 2009; 43:1143-1148.

9. Oluwajana F, Rufford C, Morrissey D. Exercise, sports and musculoskeletal medicine in UK medical school curricula: a survey. Br J Sports Med 2010; 44:i6 doi:10.1136/bjsm. 2010.078972.18.

10. Aderotimi T, Hemmings S, Morrissey D. Multidisciplinary collaboration in delivering a weight management initiative: a mixed methods evaluation $\mathrm{Br} J$ Sports Med 2011; 45:2 e1 doi:10.1136/bjsm.2010.081554.17.

11. Hemmings S, Conner A, Maffulli N, Morrissey D 2011. Specific cardiovascular disease risk factors in adolescent Whites and South Asian: A pilot study. Postgrad Med 2011; 123:104-111.

12. Mohammed U, Twycross-Lewis R, Timotijevic T, Woledge RC, Bader D, Paterson M, Coggings D, Morrissey D. Variability of kinematic and kinetic gait data in ambulatory children with spastic cerebral palsy with and without fixed ankle-foot orthoses using $3 \mathrm{~d}$ motion analysis: a quantitative prospective study. Br J Sports Med 2011; 45:e1 doi:10.1136/ bjsm.2010.081554.19.

13. Sweeney E, Chaudhry S, Screen HRC, Woledge RC, Bader D, Maffulli N, Morrissey D. The effect of eccentric and concentric loading speed on the normal Achilles tendon: an in vivo biomechanical study. $\mathrm{Br} \mathrm{J}$ Sports Med 2011; 45:e1 doi:10.1136/bjsm.2010.081554.25.

14. Fenn J, Martineau A, Wai Yee J, Islam K, Griffiths C, Maffulli N, Morrissey D. An evaluation of the relationship between vitamin $d$ status and quadriceps strength in patients with COPD: a cross sectional study. Br J Sports Med 2011; 45:e1 doi:10.1136/bjsm.2010.081554.24.

15. Dulai R, Ahmed M, Morrissey D, Twycross-Lewis R, Greenwald SE. Arterial stiffness before and after moderate intensity exercise in athletes and controls: a cross-sectional observational study Br J Sports Med 2011; 45:e1 doi:10.1136/ bjsm.2010.081554.23.

16. Jhingan S, Perry M, O'Driscoll G, Ahmad M, Maffulli N, Morrissey $\mathrm{D}$, Are asymptomatic ultrasound abnormalities in the achilles tendon of elite soccer players risk factors for symptoms one year later? a longitudinal cohort study. $\mathrm{Br} \mathrm{J}$ Sports Med 2011; 45:e1 doi:10.1136/bjsm.2010.081554.21.

17. Cleland JA, Milne A, Sinclair H, Lee AJ An intercalated BSc degree is associated with higher marks in subsequent medical school examinations. BMC Medical Education 2009; 9:24. 